American Journal of Applied Sciences 6 (1): 124-129, 2009

ISSN 1546-9239

(C) 2009 Science Publications

\title{
A Multinomial Logit Based Evaluation of the Behavior of the Life Insureds in Romania
}

\author{
${ }^{1}$ Cristian Dragos and ${ }^{2}$ Simona Dragos \\ ${ }^{1}$ Teodor Mihali Street, Nr. 58-60, S.231, 400591, Cluj Napoca, Romania \\ ${ }^{2}$ Teodor Mihali Street, Nr. 58-60, S.239, 400591, Cluj Napoca, Romania
}

\begin{abstract}
The Romanian life insurance market is in full expansion. There exists competition between insurance companies as well as between different products of the same company. In this article we describe a study using data that we collected from clients of a Romanian insurance company. We have observed two types of variables: attributes of the insurance products (e.g., profitability, risk), as well as characteristics of the individuals (e.g., sex, age, income). Using elements of economic theory and a multinomial logit model we explain the behavior of the life insureds. We estimate the variations in the market shares of life insurance products using marginal effects. The variations are due to possible changes in the values of some attributes or characteristics.
\end{abstract}

Key words: Life insurance demand, multinomial logit

\section{INTRODUCTION}

The study of the life insured's behavior has attracted the interest of a number of researchers in the past. Theoretical models on life insurance demand have been developed and empirical studies also have been conducted extensively to examine the influence of specific factors on the demand for life insurance.

This research proceeds to review the literature related to life insurance demand, to present the Romanian life insurance market, to describe the data and estimation model, to present and discuss the empirical results and to conclude with the findings of this study.

Economic theory predicts that households will save and insure in order to enjoy the same living standard over time and in the event of the death of a household head or spouse. Economic theory in this case accords with common sense and every day observation. "We save to be able to maintain our life styles in retirement. And we buy life insurance to make sure our survivors can continue to live at the same standard to which they have become accustomed" ${ }^{\text {"[1] }}$.

There is no unique theory for life insurance demand. Yaary ${ }^{[2]}$ was the first to develop a theoretical framework to study the uncertainty of lifetime and the demand for life insurance. He predicted that investors make asset allocations decisions and life insurance purchase to maximize their lifetime utilities of wealth and consumption. Almost all of the theoretical works which study the impact of wealth and bequest motives on life insurance demand developed later have expanded their models based on the study of Yaary ${ }^{[2]}$.

There are a number of empirical studies of life insurance demand that have been developed in the past. Bernheim $^{[3]}$ uses estimates of the demand for life insurance to assess the strength of bequest motives. He finds that a significant fraction of total saving is motivated by the desire to leave bequests. Browne and $\mathrm{Kim}^{[4]}$ present evidence on life insurance demand across 45 countries. They find that the main determinants of country variations in the demand for life insurance are the dependency ratio (the number of dependents per potential life insurance consumer), income, inflation and price of insurance.

The findings of Browne and $\mathrm{Kim}^{[4]}$ and Outreville $^{[5]}$ confirm that the income level affects significantly the life insurance demand. Life insurance becomes more affordable when income increases. Hwang and Greenford ${ }^{[6]}$ examine some of the key factors affecting life insurance consumption in China, Hong Kong and Taiwan. Income and life insurance consumption are found to be strongly correlated, which is consistent with previous studies. In a comparative study, Truett and Truett $^{[7]}$ examine the variables affecting life insurance demand in Mexico and in U.S. The results have shown that age, education and income impact the demand for life insurance.

Corresponding Author: Cristian Dragos, Teodor Mihali Street, No. 58-60, S.231, 400591, Cluj Napoca, Romania Tel: +040741 100478 
Over time, the life insurance decisions and the asset allocation have been analyzed separately, both in theory and practice. However, results from Headen and Lee $^{[8]}$ indicate that the demand for insurance is a function of variables such as savings, consumer sentiment and conditions if the financial market. Mayers and $\operatorname{Smith}^{[9]}$ do not agree that wealthier consumers demand less insurance and find that the benefits of an insurance policy are identified with the returns of other financial assets. These results imply that decisions to purchase insurance are not independent of decisions to make other investments.

The human capital is the factor that makes the linking between insurance and investments decisions, because it affects both the optimal asset allocation and the demand for life insurance - Ibbotson \& all ${ }^{[10]}$. They defined the human capital as the present value of an investor's future labor income.

An investor's human capital contains a unique mortality risk, which is the loss of all future income and wages in the unfortunate event of premature death. Life insurance has been used for long time to hedge against mortality risk. The greater the value of human capital is, the more life insurance the family demands.

Younger investors have far more human capital than financial capital. This is because younger investors have more years to work and they have had few years to save and accumulate financial wealth. On the other hand, young investors tend to have more financial capital than human capital, since they have fewer years ahead to work but have accumulated financial capital over a long career.

The allocation of capital in risky asset decreases as the investor ages. This result ${ }^{[11]}$ is due to the dynamic between human capital and financial wealth over time. When an investor is young, the investor's total wealth is dominated by the human capital. Since human capital in this case is less risky than the financial risky asset, young investors will invest more financial wealth into risky assets to offset the impact of human capital on the overall asset allocation. As the investor gets older, the allocation to risky assets is reduced, as human capital gets smaller.

The volume of literature on life insurance demand indicates the importance of the consumer demand for life insurance in the financial services industry. With the growing importance of insurance companies as major participants in financial markets, as well as increasing competition for investment from nontraditional institutions, this topic is likely to continue to be a popular research topic for the developed and for the developing countries.

\section{MATERIALS AND METHODS}

Our application involves clients of a Romanian insurance company, whose name will remain unrevealed, out of competition reasons. In July-August 2005, we considered a sample consisting of 203 subjects who possess insurance polices at that company. Three insurance products have been taken into consideration ${ }^{[12],}{ }^{[13]}$ : term life insurance, endowment life insurance and unit linked insurance, which altogether represent $80 \%$ of the turnover of the company.

We mention that the application is based on a middle size sample, so the conclusions must be regarded with precaution. Our target is to realize a prospective study concerning the behavior of the insured persons.

The individuals from the sample have been questioned about two kinds of variables: attributes that characterise the insurance products and characteristics of the individual that characterise the insured person ${ }^{[14]}$.

The Model: Supposing that each one of the individuals of the sample chooses only one type of life insurance, the decision of choosing the product is discreet. Consequently, the model chosen for explaining the choice of an insurance product is a discreet one, so the estimation is made using the econometrics of qualitative variables. The model is a multinomial one because the qualitative dependent variable y has more than two values, $y_{i}=j, j=0,1, \ldots, m$, respectively. In our application, the values of $y$ represent the insurance products.

The Multinomial Logit Model. The multinomial Logit is actually an extension of the binary Logit model, having more than two values for the dependent variable. Let $\left(\mathrm{p}_{0}, \mathrm{p}_{1}, \ldots, \mathrm{p}_{\mathrm{m}}\right)$ be the probabilities of $\mathrm{m}+1$ alternatives of choice. The probability of an individual $i$ to choose the alternative $\mathrm{j}$ is given by:

$$
p_{i j}=P\left(y_{i}=j\right)=\frac{\exp \left(x_{i} b_{j}\right)}{1+\sum_{j=1}^{m} \exp \left(x_{i} b_{j}\right)} \quad j=1,2, \ldots, m
$$

where, $x_{i}$ is the vector of the independent variables associated to the individual $i$ and $b_{j}$ is the vector of parameters associated to the alternative $j$. 
The Conditional Multinomial Logit Model. The generalization of the Logit model for the multinomial case is made by taking different parameters $b_{j}$ depending on the alternatives of choice (products), such that the idependent variables $\mathrm{x}_{\mathrm{i}}$ remain constants depending on the products. Still, there is another possibility: the McFadden conditional Logit model which considers a constant vector of parameters $b$ and allows the independent variables $\mathrm{x}_{\mathrm{ij}}$ to depend on the alternatives $\left(\mathrm{McFadde}^{[15],[16]}\right)$. The probability of an individual $i$ to choose the product $\mathrm{j}$ is given by:

$$
\mathrm{p}_{\mathrm{ij}}=P\left(\mathrm{y}_{\mathrm{i}}=\mathrm{j}\right)=\frac{\exp \left(\mathrm{x}_{\mathrm{ij}} \mathrm{b}\right)}{\sum_{\mathrm{k}=1}^{\mathrm{m}} \exp \left(\mathrm{x}_{\mathrm{ik}} \mathrm{b}\right)}=\frac{\exp \left(\mathrm{x}_{\mathrm{ij}}^{*} \mathrm{~b}\right)}{1+\sum_{\mathrm{k}=1}^{\mathrm{m}} \exp \left(\mathrm{x}_{\mathrm{ik}}^{*} \mathrm{~b}\right)}
$$

$$
\mathrm{j}=1,2, \ldots, \mathrm{m}
$$

where, $x_{i j}^{*}=x_{i j}-x_{i 0}$ and the ratio of the probabilities is:

$$
\begin{array}{r}
\frac{P\left(y_{i}=j\right)}{P\left(y_{i}=1\right)}=\frac{\exp \left(x_{i j}^{*} b\right)}{\exp \left(x_{i j}^{*} b\right)}=\frac{\exp \left(x_{i j} b\right)}{\exp \left(x_{i l} b\right)}=\exp \left[\left(x_{i j}-x_{i l}\right) b\right] \\
\forall j, 1=1,2, \ldots, m
\end{array}
$$

which, as in the case of the multinomial Logit is independent of the other alternatives of choice.

When computing the marginal effects, we are interested in the estimated variation of the probability of an individual $\mathrm{i}$ to choose the product $\mathrm{j}$, when the independent variable $\mathrm{k}$ associated to a product varies. We have:

$$
\mathrm{p}_{\mathrm{ij}}=\frac{\exp \left(\sum_{\mathrm{k}=1}^{\mathrm{K}} \mathrm{x}_{\mathrm{ijk}} \mathrm{b}_{\mathrm{k}}\right)}{1+\sum_{\mathrm{h}=1}^{\mathrm{m}} \exp \left(\sum_{\mathrm{k}=1}^{\mathrm{K}} \mathrm{x}_{\mathrm{ink}} \mathrm{b}_{\mathrm{k}}\right)}
$$

the marginal effect $\frac{\partial \mathrm{p}_{\mathrm{ij}}}{\partial \mathrm{x}_{\mathrm{ilk}}}$ being:

$$
\left\{\begin{array}{cc}
b_{k} p_{i j}\left(1-p_{i j}\right) & \text { if } j=1 \\
-b_{k} p_{i j}\left(1-p_{i 1}\right) & \text { if } j \neq 1
\end{array}\right.
$$

The General Multinomial Logit Model. Due to the fact that our application involves both attributes of the products and characteristics of the individual, we use a more general model, which contains both the multinomial and the conditional logit models ${ }^{[15],[17],],[18]}$. The probability for an individual $i$ to choose the alternative $\mathrm{j}$ is given by: $p_{i j}=P\left(y_{i}=j\right)=\frac{\exp \left(x_{i j} b+x_{i} b_{j}\right)}{\sum_{k=1}^{m} \exp \left(x_{i k} b+x_{i} b_{k}\right)} \quad j, k=0,1,2, \ldots, m$

Once the parameters have been estimated, by replacing the values of the explicative variables with the mean values from the sample, we can obtain an estimation of the probability $\tilde{p}_{\mathrm{j}}$ that a randomly chosen individual (average individual) will choose the product $\mathrm{j}$. By multiplying this number by the total number of consumers $\mathrm{N}$, an estimation of the demand (or of the market share) for the product $\mathrm{j}$ can be obtained:

$$
\tilde{D}_{\mathrm{j}}=\tilde{\mathrm{p}}_{\mathrm{j}} \times \mathrm{N}
$$

We can also obtain simulated market shares for products, computed for other values of the explicative variables, thus facilitating the foundation of some product policies.

\section{The variables:}

Profitability-values from 1 to 10

Risk-values from 1 to 10

Age-years

Sex-0 if the individual is a woman, 1 if it is a man

Income-RON/month

Term-dummy variable. Equal to 1 if the term life insurance product is chosen, 0 otherwise

Endowment-dummy variable. Equal to 1 if the endowment insurance product is chosen, 0 otherwise

Unit linked-dummy variable. Equal to 1 if the unit linked insurance product is chosen, 0 otherwise

Age_term $=$ Age $\times$ Term

Age_endowment $=$ Age $\times$ Endowment

Age_unit linked $=$ Age $\times$ Unit linked

Sex_term $=$ Sex $\times$ Term

Sex_endowment $=$ Sex $\times$ Endowment

Sex_unit linked $=$ Sex $\times$ Unit linked

Income_unit linked $=$ Income $\times$ Unit linked

Income_endowment $=$ Income $\times$ Endowment

Income_unit linked = Income $\times$ Unit linked

\section{RESULTS AND DISCUSSION}

Before estimating the parameters of the model, we present some descriptive statistics regarding the data from the sample (Table 1).

The estimation of the model: For estimating the parameters we use the econometric software LIMDEP 
Am. J. Applied Sci., 6 (1): 124-129, 2009

7.0 and the Newton-Raphson method like estimation algorithm (Table 2).

The values of the parameters are according to expectations. The positive sign for profitability shows an increased probability of choosing the product when the value of the variable increases. The negative sign for risk shows a decrease of probability. The negative signs for age_endowment and age_unit linked show that when age increases, it decreases the probability of choosing the endowment insurance and unit linked insurance products, with respect to the reference product, the term insurance. The parameter of the sex endowment variable is not statistically significant. The positive sign for sex_unit linked shows that it is more likely for men to choose unit linked insurances than women. The negative signs for income_endowment and income_unit linked show that when income increases, it increases the probability of choosing the endowment insurance and unit linked insurance products, with respect to the reference product, the term insurance.

Table 1: The average values of variables in the sample

\begin{tabular}{|c|c|c|c|c|c|}
\hline & \multicolumn{5}{|l|}{ Variables } \\
\hline & Profitability & Risk & Age & $\begin{array}{l}\text { Sex (\% } \\
\text { of males) }\end{array}$ & $\begin{array}{l}\text { Income } \\
\text { (RON/month) }\end{array}$ \\
\hline Term & 4.70 & 5.87 & 59.3 & 34.0 & 807 \\
\hline Endowment & 3.01 & 1.87 & 50.0 & 48.6 & 934 \\
\hline Unit linked & 8.37 & 6.71 & 40.6 & 63.9 & 1109 \\
\hline
\end{tabular}

Table 2: Parameters estimates. Discrete choice (multinomial logit) model

\begin{tabular}{llll}
\hline Variable & Coefficient & Standard dev. & t-statistic \\
\hline Profitability*** & 0.5977 & 0.1421 & 4.206 \\
Risk*** & -1.1344 & 0.1809 & -6.268 \\
Age_term & 0.000 & Fixed parameter & - \\
Age_endowment*** & -0.0978 & 0.0193 & 5.068 \\
Age_unit linked*** & -0.1785 & 0.0258 & 6.915 \\
Sex_term & 0.000 & Fixed parameter & - \\
Sex_endowment & 0.5516 & 0.5199 & 1.061 \\
Sex_unit linked** & 1.2394 & 0.6143 & 2.017 \\
Income_term & 0.000 & Fixed parameter & - \\
Income_endowment** & 0.0027 & 0.0013 & 2.102 \\
Income_unit linked**** & 0.0084 & 0.0015 & 5.641 \\
$\mathrm{~N}=203 \mathrm{R}^{2}=0.485$ & & & \\
\hline$* * *: \mathrm{p}<0.01, * *: \mathrm{p}<0.05, *: \mathrm{p}<0.10$ & &
\end{tabular}

Table 3: Predicted probabilities

\begin{tabular}{llll}
\hline Indiv. & Term & Endowment & Unit_linked \\
\hline 1 & $0.9330^{*}+$ & 0.0666 & 0.0004 \\
2 & $0.7582^{*}+$ & 0.1785 & 0.0633 \\
3 & $0.1264^{*}$ & $0.6861+$ & 0.1875 \\
$\ldots$ & $\ldots$ & $\ldots$ & $\ldots$ \\
55 & 0.0441 & $0.1667^{*}$ & $0.7892+$ \\
56 & 0.2634 & $0.6446^{*}+$ & 0.0920 \\
$\ldots$ & $\ldots$ & $\ldots$ & $\ldots$ \\
201 & 0.2787 & 0.2461 & $0.4751^{*+}$ \\
202 & 0.0030 & 0.0649 & $0.9321^{*}$ \\
203 & 0.3869 & $0.4878+$ & $0.1253^{*}$ \\
\hline
\end{tabular}

*: Marks chosen,+: Marks prediction
Table 4: The marginal effects (\%) for the variable profitability

\begin{tabular}{lllll}
\hline & & \multicolumn{2}{l}{ The marginal effect over the } \\
& & & \\
& & & & Unoduct \\
& & Term & & Unit \\
& & insurance & Endowment & linked \\
\hline The product & Term & 4.79 & -3.59 & -1.20 \\
for which & Endowment & -3.59 & 8.92 & -5.33 \\
profitability varies & Unit linked & -1.20 & -5.33 & 6.53 \\
\hline
\end{tabular}

For each individual, we can compute according to the formula (6) the probability of choosing each of the three insurance products (Table 3 ).

A study of the estimated probabilities shows that the model is a pertinent one from the point of view of predictions, the percentage of correct predictions in the sample being $72.9 \%$.

The applicability of the model: We may consider the case when the values of the explicative variables change. We compute the marginal effects, the percentage variations of the share markets of the products respectively, when the profitability and risk variables are increased by 1 (Table 4 ).

The results obtained are according to expectations: the increase of the profitability for a product determines the increase of its market share and the decrease of the market shares for the other products, but of different values. For instance, the increase of profitability for the

Table 5: The marginal effects (\%) for the variable risk

\begin{tabular}{lllcc}
\hline & & \multicolumn{2}{l}{ The marginal effect over the product } \\
& & - & Term & \\
& & & Unit \\
& & insurance & Endowment & linked \\
\hline The product & Term & -9.10 & 06.82 & 02.28 \\
For which & Endowment & 6.82 & -16.93 & 10.11 \\
risk varies & Unit Linked & 2.28 & 10.11 & -12.39 \\
\hline
\end{tabular}

Table 6: Estimated market shares for the insurance products (group age: $50-60$ years)

\begin{tabular}{lllllllll}
\hline & \multicolumn{2}{l}{ Income (RON/month) } & & & & \\
& - & -- & - & - & & & & \\
& 700 & 800 & 900 & 1000 & 1100 & 1200 & 1300 & 1400 \\
\hline Term & 39.6 & 31.9 & 24.4 & 17.4 & 11.3 & 06.7 & 03.6 & 01.8 \\
Endowment & 55.4 & 58.7 & 59.0 & 55.1 & 47.1 & 36.5 & 25.7 & 16.7 \\
Unit Linked & 05.0 & 09.4 & 16.6 & 27.5 & 41.6 & 56.8 & 70.7 & 81.5 \\
\hline
\end{tabular}

Table 7: Estimated market shares for the insurance products (income $=1.000 \mathrm{RON} /$ month)

\begin{tabular}{llllllllll}
\hline & Age & & & & & & & & \\
& 35 & 40 & 45 & 50 & 55 & 60 & 65 & 70 & 75 \\
\hline Term & 01.2 & 02.6 & 05.3 & 09.9 & 17.4 & 27.8 & 40.6 & 54.3 & 66.9 \\
Endowment & 28.2 & 36.4 & 44.7 & 51.6 & 55.1 & 54.2 & 48.6 & 39.8 & 30.1 \\
Unit Linked & 70.6 & 61.0 & 50.0 & 38.5 & 27.5 & 18.0 & 10.8 & 5.9 & 03.0 \\
\hline
\end{tabular}




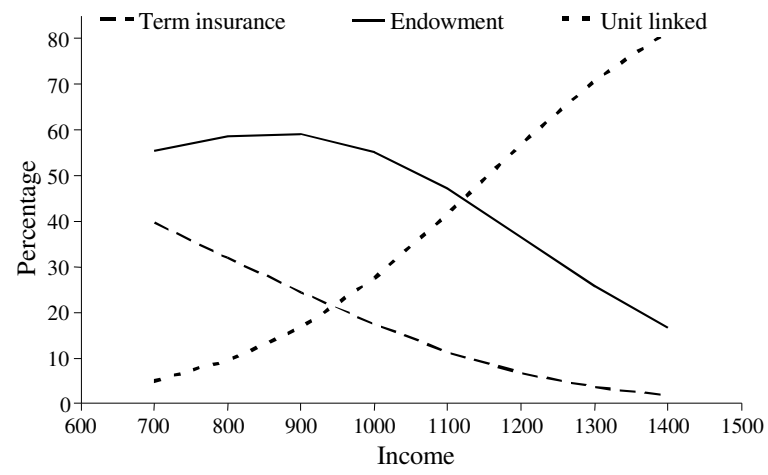

Fig. 1: The evolution of the insurance products with respect to the income (55 years old person)

term insurances will have a greater impact on the endowment insurances than on the unit linked ones (Table 5).

For the risk variable, the results are very similar, but of opposite sign: when the risk of a product increases its market share decreases and the market share for the other products increase (Table 6, Fig. 1).

The model can be also used for building some product strategies (advertising, promotion). Considering this, we estimate the markets shares of the three insurance products, for different values of the variables income and age. The variables profitability and risk keep their average values from the sample (Table 7, Fig. 2).

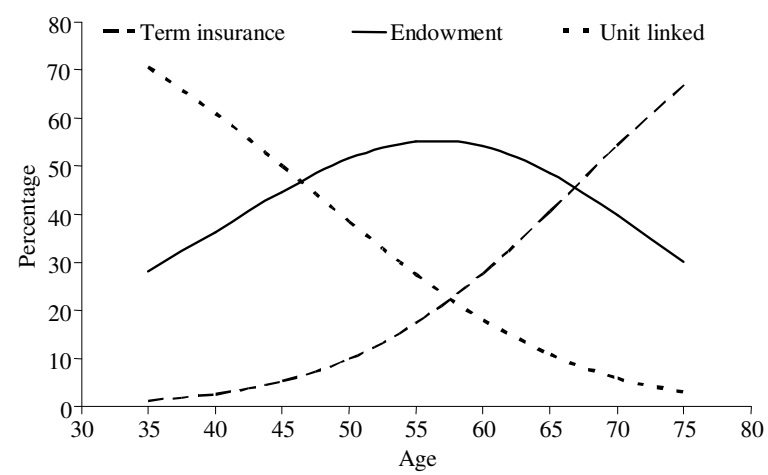

Fig. 2: The evolution of the insurance products with respect to the age (income $=1000 \mathrm{RON} /$ month)

\section{CONCLUSION}

All in all, we have succeeded to explain through multinomial logit model different aspects of the behavior of the life insureds in a company from the Romanian insurance market. The results obtained in the application match perfectly to the theory presented previously. The demand for products with lower risk level increases, as a person is getting older, to the detriment of the products of higher risk level. Moreover, the income is a major factor that influences the choice of a specific insurance product: as income increases, there exists an increased affordability for the higher risk products.

The demand for each product is well predicted as well as the attributes of the products (and characteristics of the individuals) that determine the choice. The model can be used by modifying the characteristics of the life insurance products, in order to obtain among these a relation that would maximize the profit of the company. One insurance product may be more profitable than another, while the achievement of a demand structure, as profitable as possible for the company, can be determined based on the estimations of the marginal effects of the risk and of the profitability of insurance products.

This study is a prospective one; the sample is not highly significant. Although, the model can explain the behaviour of the life insured and can be a base for further studies capable to estimate more precisely the demand for different types of insurances.

\section{REFERENCES}

1. Kotlikoff, J., Gokhale, M., 2002. The Adequacy of Life Insurance, Tiaa-Cref Institute Research Dialogue, no.72.

2. Yaary, M.E., 1964. On Consumer's Lifetime Allocation Process, International Economic Review, 5 (3): 304-317.

3. Bernheim, B., 1991. How Strong are Bequest Motives? Evidence Based on Estimates of the Demand for Life Insurance and Annuities, Journal of Political Economy, 99: 899-927.

4. Browne, M., Kim, K., 1993. An International Analysis of Life Insurance Demand, Journal of Risk and Insurance, 60 (4): 601-634.

5. Outreville, J.F., 1996. Life Insurance Markets in Developing Countries, Journal of Risk and Insurance, 63 (1): 132-152.

6. Hwang, T., Greenford, B., 2005. A Cross-Section Analysis of the Determinants of Life Insurance Companies in Mainland China, Hong Kong and Taiwan, Risk Management and Insurance Review, 8 (1): 103-125.

7. Truett D.B., Truett L.J., 1990. The Demand for Life Insurance in Mexico and the United States: A Comparative Study, Journal of Risk and Insurance, 57: 321-328. 
8. Headen R.S., Lee J.F.,1974. Life Insurance Demand and Household Portfolio Behaviour, Journal of Risk and Insurance, 67: 685-698.

9. Mayers, D., Smith, C.W., 1983. The Interdependence of Individual Portfolio Decision ans the Demand for Insurance, Journal of Political Economy, (91): 304-311.

10. Ibbotson, R. \& al., 2005. Human Capital Asset Allocation and Life Insurance, ICF Working Paper, Yale-International Center for Finance.

11. Haberman, S., Lim, C., 2004. Modelling Life Insurance Demand from a Macroeconomic Perspective: The Malaysian Case, Proceedings of the Eight International Congress on Insurance: Mathematics \& Economics, London.

12. Report for the Romanian Insurance Market, 2004. The Insurance Supervision Commission.

13. Insurance Profile - Romanian Insurance Market, 2004. Quarterly Insurance Review, 4.
14. Dragos, C., Dragos, S., 2005. The Demand for Different Life Insurance Products. A Discrete Choice Model Approach, 10 ${ }^{\text {th }}$ International Conference on Finance and Banking, Karvina, Czech Republic, 1319-1337.

15. McFadden, D., 1973. Conditional Logit Analysis of Qualitative Choice Behaviour, Frontiers in Econometrics, Academic Press, New York, 105142.

16. McFadden, D., 1980. Econometric Models of Probabilistic Choice among Products, Journal of Bussines, 53: 513-529.

17. Hausman, J., McFadden, D., 1984. Specification Tests for the Multinomial Logit model, Econometrica, 52: 1219-1240.

18. Berry S., 1994. Estimating Discrete Choice Models of Product Differentiation, RAND Journal of Economics, 25: 242-262. 